\title{
Incorporation of Alkylthiol Chains at C-5 of Deoxyuridine
}

\author{
Jay T. Goodwin and Gary D. Glick*1 \\ Department of Chemistry \\ University of Michigan \\ Ann Atbor, Michigan 48109-1055 U.S.A.
}

Key Words: Alkylthiol-modified nucleosides; disulfide crasslinks

\begin{abstract}
A series of alkylthiol-tether homologs at C-5 of 2'-deoxyuridine have been synthesized and incorporated into DNA oligomers through solid-phase DNA phosphoramidive synthesis. DNA-ligand disulfide crosslinks have been initially addressed through formation of an $n$-butyl-DNA disulfide conjugate.
\end{abstract}

A wide variety of nucleoside modifications have recently been developed to aid in the study of DNA and RNA structures and their interactions with various ligands. ${ }^{2}$ We have recently introduced a method of conformationally restricting native ${ }^{3}$ and non-groundstate 4 DNA secondary structures through site-specific incorporation of disulfide crosslinks. Because of our ongoing studies of these and other DNA and RNA structures we have engendered the need for greater

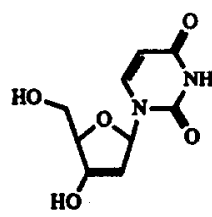

Deoxyuridine

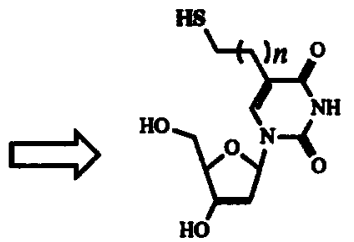

C-5-modified deoxyuridine; $n=1-3$ flexibility in the location and length of the alkylthiol linker. The $\mathrm{C}-5$ position of deoxyuridine has been the target of extensive modifications. ${ }^{5}$ When incorporated into duplex B-DNA such modifications are located in the major groove, ${ }^{6}$ and so do not disrupt Watson-Crick base pairing. We report here the synthesis of the three-, four-, and five-atom alkylthiol linker homologs at C-5 of deoxyuridine, ${ }^{7}$ their incorporation into DNA oligomers through solid-phase phosphoramidite chemistry, and preliminary results concerning their participation in DNA-alkyl disulfide crosslinks.

Synthesis of the four- and five-atom linkers was initiated through palladium-catalyzed coupling of 2'deoxy-5-iodouridine with the corresponding acetylenic alcohol, ${ }^{8}$ followed by hydrogenation' to yield the saturated primary alcohols in $60-70 \%$ overall yield for three steps. The three-atom alcohol precursor was obtained via palladium-catalyzed coupling of 5-chloromercuri-2'-deoxyuridine ${ }^{10}$ with allyl chloride, ${ }^{11}$ quantitative silylation of the hydroxyl groups, ${ }^{12}$ followed by oxidation of the terminal olefin to the aldehyde ${ }^{13}$ and reduction to the primary alcohol in 55\% overall yield. Subsequent chemistry was the same for all three homologs. The alcohol was transformed to the thiol by activation as the mesylate followed by displacement with thiobenzoic acid, with subsequent exchange ${ }^{14}$ to the $t$-butyl disulfide in an average yield of $60-70 \%$ for three steps. Removal of the silyl protecting groups with tetra- $n$-butylammonium fluoride followed by protection of the 5'-alcohol as the dimethoxytrityl ether and functionalization of the 3'-hydroxyl as the phosphoramidite $3 a, 15$ provided the fully protected C-5-modified deoxyuridine as required for solid-phase 


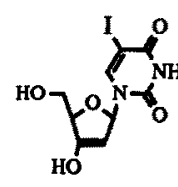<smiles>C[18OH]</smiles>

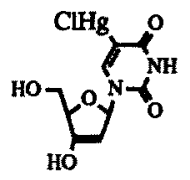

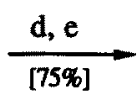

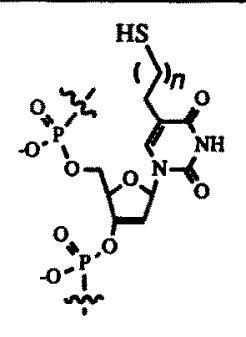

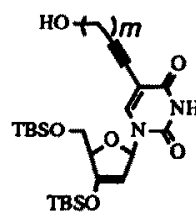

$$
1-\mathrm{a}(m=1) ;-\mathrm{b}(m=2)
$$

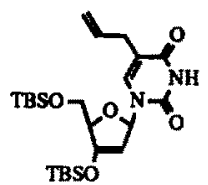

1.c

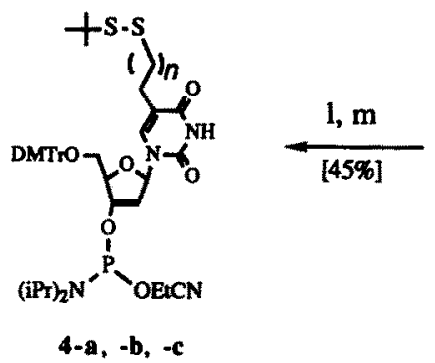
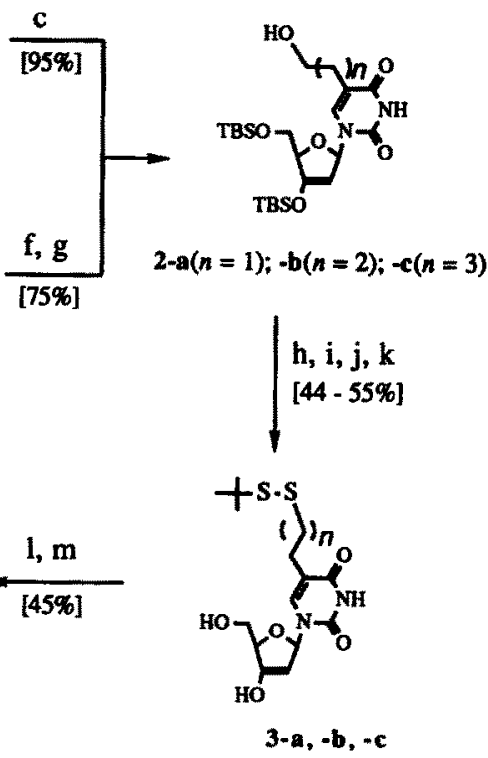

Scheme I. (a) $t$-BDMSiCl, imidazole, DMF; (b) propargyl alcohol $(m=1)$; 3-butyn-1-ol $(m=2)$, Pd(PPh $)_{4}$, $\mathrm{CuI}, \mathrm{Et} 3 \mathrm{~N}, \mathrm{DMF}$; (c) $\mathrm{H}_{2}, \mathrm{Pd}-\mathrm{C}$, MeOH; (d) allyl chloride, $\mathrm{Li}_{2} \mathrm{PdCl}_{4}, \mathrm{MeOH}$; (e) $t-\mathrm{BDMSiCl}_{\text {, imidazole, DMF; }}$ (f) $\mathrm{OxO}_{4}$, n-methylmorpholine-n-oxide, acetone/ $/ \mathrm{H}_{2} \mathrm{O} ; \mathrm{NaIO}_{4}$, dioxane/ $\mathrm{H}_{2} \mathrm{O} ;(\mathrm{g}) \mathrm{NaBH}, \mathrm{MeOH}$; (h) methanesulfonyl chloride, pyridine, $\mathrm{MeCl}_{2}$; (i) thiobenzoic acid, Et $3 \mathrm{~N}, \mathrm{DMF}$; (j) 1-t-butylthiohydrazine-1,2-dicarboxmorpholide, LiOH, $\mathrm{MeOH}$; (k) n-Bu, NF, THF; (l) DMTrCl, pyridine; (m) 2-cyanoethyl- $N, N$-diisopropylchlorophosphoramidite, $i-\mathrm{P}_{2} \mathrm{E}$, $\mathrm{MeCl}_{2}$.

DNA synthesis. The $t$-butyl disulfide protecting group for the thiol is stable to the reagents utilized during DNA synthesis, and is readily removed by treatment with dithiothreitol (DTT) following detritylation and deprotection of the bases. 16

As an example of the utility of the C-5-alkylthiol modification 4-a (represented as $\mathbb{T}$ ) has been incorporated into the DNA pentamer 5'-dTACTG (I) and has been shown to retain its integrity by a positive Ellman's test ${ }^{17}$ and enzymatic degradation ${ }^{3 a}$ to the constituent mononucleosides. The selective chemistry of disulfide formation has been utilized in preparation of a variety of DNA-protein conjugates at either the $5^{\prime}-18$ or $3^{\prime}$-termini. ${ }^{19}$ Complimentary

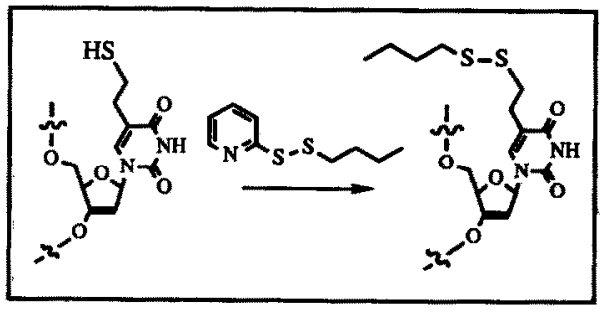
to these techniques we have prepared the $n$-butyl-DNA disulfide conjugate of I by treatment with the pyridyl$n$-butyl mixed disulfide, and have verified the product composition by enzymatic degradation (FIGURE 1). 


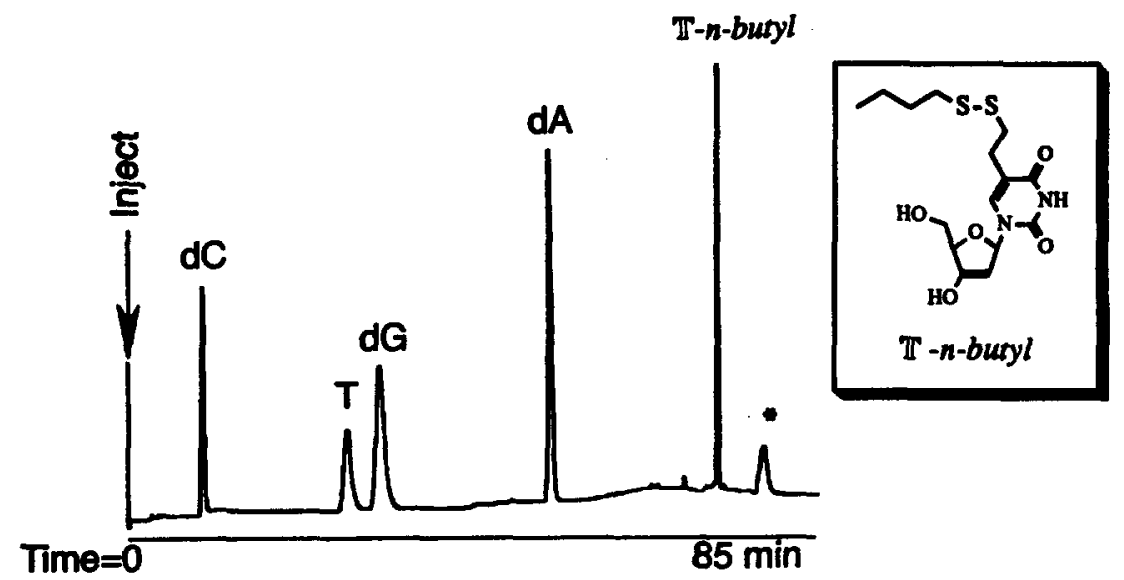

FIGURE 1: Reversed-phase HPLC profile of enzymatic degradation of $n$-butyl-I disulfide conjugate; the asterisk denotes uncharacterized material from the enzyme buffer. Conditions: $\mu$ Bondapak $\mathrm{C}-18$ column; $0.1 \mathrm{M}$ triethylammonium acetate, $\mathrm{pH} 6.6$, with a convex gradient to $15 \% \mathrm{CH}_{3} \mathrm{CN}$ in $60 \mathrm{~min}$, then a linear gradient to $90 \% \mathrm{CH}_{3} \mathrm{CN}$ in 30 min.

In conclusion we have functionalized the C-5 position of deoxyuridine with a series of alkylthiol homologs, have site-specifically incorporated them into DNA oligomers, and have characterized a DNA- $n$ butyl disulfide conjugate. We are currently utilizing these modified deoxynucleosides in the generation of disulfide-stabilized DNA triple helices ${ }^{20}$ and are extending the methodology to the study of DNA major groove-peptide conjugates and various RNA secondary and tertiary structures.

\section{REFERENCES AND NOTES}

1. Recipient of a National Arthritis Foundation Arthritis Investigator Award (1992-1994), an American Cancer Society Junior Faculty Research Award (1993-1996), and a National Science Foundation Young Investigator Award (1993-1998).

2. For a recent review see: Englisch, U.; Gauss, D.H. Angew. Chem. Int. Ed. Engl. 1991, 30, 613.

3. a. Glick, G.D. J. Org. Chem. 1991, 56, 6746. b. See also: Carbon, J.; David, H. Biochemistry 1968, 7, 3851; Ferentz, A.E.; Verdine, G.L. J. Am. Chem. Soc. 1991, 113, 4000.

4. Glick, G.D.; Osbome, S.E.; Knitt, D.E.; Marino, J.P., Jr. J. Am. Chem. Soc. 1992, 114 , 5447. 
5. Prober, J.M.; et al. Science 1987, 238, 336; Langer, P.R.; Waldrop, A.A.; Ward, D.C. Proc. Natl. Acad. Sci. USA 1981, 78, 6633; Telser, J.; Cruickshank, K.A.; Morrison, L.E.; Netzel, T.L. J. Am. Chem. Soc. $1989,111,6966$.

6. Froehler, B.C.; Wadwani, S.; Terhorst, T.J.; Gerrard, S.R. Tetrahedron Lett. 1992, 33, 5307.

7. For the analogous one-atom thiol linker see: Bradley, D.H.; Hanna, M.M. Tetrahedron Lett. 1992, 33 , 6223.

8. Hobbs, F.W., Jr. J. Org. Chem. 1989, 54, 3420.

9. Gibson, K.J.; Benkovic, S.J. Nucl. Acids Res. 1987, 15, 6455.

10. Dreyer, G.B.; Dervan, P.B. Proc. Natl. Acad. Sci. USA 1985, 82, 968.

11. Ruth, J.L.; Bergstrom, D.E. J. Org. Chem. 1978, 43, 2870.

12. Ogilvie, K.K. Can. J. Chem. 1973, 51, 3799.

13. Vedejs, E.; et al. J. Am. Chem. Soc. 1987, I09, 5437; Fiandor, J.; Tam, S.Y. Tetrahedron Lett. 1990, 31 , 597.

14. Wünsch, E.; Moroder, L.; Romani, S. Hoppe-Seyler's Z. Physiol. Chem. 1982, 363, 1461.

15. All modified nucleosides gave ${ }^{1} \mathrm{H}-,{ }^{13} \mathrm{C}$-NMR, and mass spectra consistent with the proposed structures.

16. The $t$-butyl disulfide is cleaved with 100 equivalents of DTT, pH 8, at room temperanure within 24 hours.

17. Ellman, G.L. Arch. Biochem. Biophys. 1959, 82, 70.

18. Chu, B.C.F.; Orgel, L.E. Nucl. Acids Res. 1988, 16, 3671.

19. Zuckerman, R.; Corey, D.; Schultz, P. Nucl. Acids Res. 1987, 15, 5305.

20. Goodwin, J.T.; Osborne, S.E.; Glick, G.D. manuscript in preparation.

(Received in USA 27 May 1993; accepted 9 July 1993) 